\title{
Peripheral Nerve Regeneration: Current Status and New Strategies Using Polymeric Materials
}

\author{
Ana C. Pinho, Ana C. Fonseca, Arménio C. Serra, José D. Santos, and Jorge F. J. Coelho*
}

Experiments concerning peripheral nerve regeneration have been reported since the end of the $19^{\text {th }}$ century. The need to implement an effective surgical procedure in terms of functional recovery has resulted in the appearance of several approaches to solve this problem. Nerve autograft was the first approach studied and is still considered the gold standard. Since autografts require donor harvesting, other strategies involving the use of natural materials have also been studied. Nevertheless, the results were not very encouraging and attention has moved towards the use of nerve conduits made from polymers, whose properties can be easily tailored and which allow the nerve conduit to be easily processed into a variety of shapes and forms. Some of these materials are already approved by the US Food and Drug Administration (FDA), as is presented here. Furthermore, polymers with conductive properties have very recently been subject to intensive study in this field, since it is believed that such properties have a positive influence in the regeneration of the new axons. This manuscript intends to give a global view of the mechanisms involved in peripheral nerve regeneration and the main strategies used to recover motor and sensorial function of injured nerves.

\section{Introduction}

Peripheral nerve injuries represent a common disability around the world. ${ }^{[1]}$ Indeed, annually more than one million people suffer from this kind of injury, with 300000 of these cases in Europe alone. ${ }^{[2]}$

Injuries in the peripheral nervous system can result from working accidents, motor vehicle accidents, tumor damage, side effects of neurosurgery and even viral infections. ${ }^{[1,3]}$ For this reason, the development of suitable methods to properly regenerate these injuries is mandatory and represents a worldwide social need.

\footnotetext{
A. C. Pinho, Dr. A. C. Fonseca, Prof. A. C. Serra, Prof. J. F. J. Coelho

CEMUC

Department of Chemical Engineering

University of Coimbra

Rua Sílvio Lima-Pólo II, 3030-790 Coimbra, Portugal

E-mail: jcoelho@eq.uc.pt

Prof. J. D. Santos

CEMUC

Department of Metallurgical and Materials Engineering University of Porto

Rua Dr Roberto Frias, 4200-465 Porto, Portugal
}

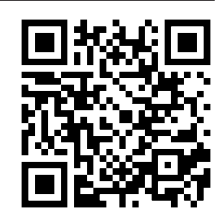

DOI: 10.1002/adhm.201600236
For the last 100 years, examples of degeneration and regeneration of the nervous system have been described in literature. ${ }^{4]}$ However, during the first 40 years of investigation, the regeneration process was not completely known. During that period, nerve autografts and allografts were the standard techniques used to treat the transected nerves. Unfortunately, these techniques present several disadvantages, the worst being related to high morbidity and the need for immunosuppression treatments. Since the peripheral nervous system has the ability to regenerate, new approaches using nerve guide tubes, also known as nerve guide conduits (NGC), have been studied. A NGC can be defined as a tube that is sutured or fixed to the two stumps of the injured nerve and provides an adequate environment for the nerve regeneration.

Nowadays, it is well established that nerve conduits are responsible for guiding axon migration, maintaining the nerve growth factors in the space between distal and proximal stumps and preventing the wound healing space from being invaded by scar tissue and cells that could compromise the nerve recovery process. ${ }^{[5]}$

Nerve conduits made of several kinds of materials have been tested throughout the years. Among such materials, natural and synthetic polymers have been the most used and several nerve conduits based on such materials are already commercially available.

This review intends to provide an overview of the regeneration events that occur after a nerve injury, the strategies to promote the functional recovery of the injured nerve and the role of the materials that are being used to produce NGC.

\section{Nervous System Regeneration}

The first event occurring after a peripheral nerve injury is a series of cellular and molecular events called Wallerian degeneration, and was described for the first time by August Waller in $1850 .{ }^{[5,6]}$ During this step, the myelin sheath is degraded and several axon ends are sealed, resulting in the disintegration of neurofilaments and microtubes. ${ }^{[7-9]}$ Meanwhile, the metabolism of proteins is changed, resulting in the increased synthesis of regenerative materials and Schwann cells. These cells 
start forming structures with a tube shape, known as bands of Büngner, in order to provide guidance for axon regeneration. ${ }^{[10]}$ Also, they produce extracellular matrix molecules and neurotrophic factors that have a positive influence on the sprouting of new axons from the terminal nodes of Ranvier. ${ }^{[7,11]}$ Although peripheral nervous system (PNS) axons can be fully regenerated, the recovery of the function is very unusual and unsatisfactory, especially for large gaps. Due to this fact, microsurgical techniques were introduced by Millesi in the 1960s in order to improve the healing of this kind of injuries. ${ }^{[12]}$ The first attempts consisted on simply suturing the nerve stumps (neurorhaphy). However, excessive tension between the two stumps can be harmful, ${ }^{[13]}$ leading to unsatisfactory results, as functional recovery could not be achieved. Currently, to classify PNS injuries there are two different models: Seddon and Sunderland. ${ }^{[14,15]}$ The description of each classification is presented in Table 1.

In the most severe cases, as shown in Table 1, surgery is needed for the reconstruction of the nerve. Many approaches have appeared, nerve autographing being the most popular. Briefly, nerve autographing consists in harvesting a nerve segment from another site of the body to gather the stumps of the injured nerve. However, nerve autographing presents several disadvantages such as tissue availability, differences in tissue size and structure, and donor site morbidity. ${ }^{[17]}$ In order to overcome these disadvantages, NGC has started to be used.

\section{Ideal Nerve Guide Conduit Properties}

In 1882, a NGC was successfully tested for the first time in a dog nerve gap of $30 \mathrm{~mm}$, bridged by a hollow bone tube. ${ }^{[18]}$ Since then, many attempts to produce the ideal NGC have been reported and some of them were used in clinical trials in humans. The concept behind the NGC is to create a tubular structure that could bridge the two sections of the previously injured axon, providing guidance for the new axons and protect them from the scarred tissue that is formed within just a few days. ${ }^{[19]}$ The main aim of this strategy is to increase the probability of axon regeneration as well as their length and growth speed.

Nowadays, it is believed that a NGC should be capable of providing mechanical support for the new fibers, guide the regenerated axons from the proximal to distal nerve stump, avoid scarred tissue infiltration and behave like a channel that allows the diffusion of neurotropic and neurotrophic factors secreted by the nerve stumps. ${ }^{[20]}$ Basically, these structures should provide an adequate microenvironment for nerve regeneration. Figure 1 represents the steps that occur when regeneration of a nerve includes a tube guide.

Among the advantages of these 3D structures, in comparison to the old method of suturing the two stumps, is the possibility of stressing the reduction in neuroma, scar formation and collateral sprouting of the new axons. ${ }^{[21]}$ Furthermore, as the neurotrophic factors secreted by the stumps become trapped inside the conduit, an accumulation occurs resulting in a higher concentration of such molecules that favor nerve regeneration. Their ability to provide a pathway for the new fibers to achieve the distal stump makes them a suitable choice for the regeneration of the nerve and recovery of its functionality.

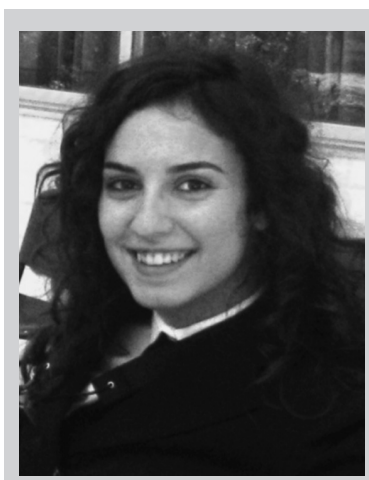

Ana C. Pinho was born in Oliveira de Azeméis, Portugal, in 1989. She graduated from the Faculty of Science and Technology of the University of Coimbra, Portugal, in Materials Engineering with focus on Biomaterials, in 2012. Currently, she is currently a PhD student at the University of Coimbra. Her research work deals with the development of new polymers to be used in peripheral nerve regeneration.

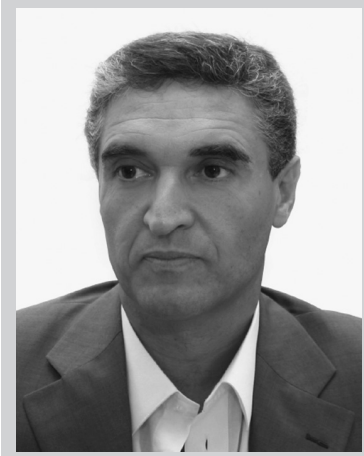

José D. Santos is currently Associate Professor with Habilitation (Aggregation) at FEUP-Faculty of Engineering, University of Porto (2005present) and is presently researcher of CEMUC - Centro de Engenharia Mecânica da Universidade de Coimbra, and coordinator for the Research line "Advanced Materials, Technologies Q Structures for Health". He developed all the experimental work for his $\mathrm{PhD}$ at IRC in Biomedical Materials, University of London, and in 1993 obtained his PhD at FEUP, where he has spent his academic career to date.

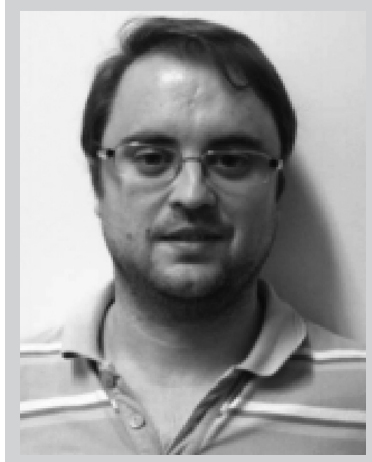

Jorge F. J. Coelho was born in Figueira da Foz, Portugal, in 1978. In 2006, he obtained his PhD from the University of Coimbra working on new living radical polymerization methods for vinyl chloride. Currently he is an assistant professor with habilitation (Aggregation) at the University of Coimbra. His research interests include living radical polymerization,

bio-based and biodegradable polymers, novel pharmaceutical products, supramolecular chemistry and scale-up approaches for living radical polymerization.

Regarding the main properties that these devices must have, the most important are: biocompatibility, biodegradability, permeability, biomechanical properties, surface properties, custom dimension and interaction with neurotrophic factors. ${ }^{\text {[2-25] }}$

The biocompatibility of NGCs is evaluated considering three aspects: blood compatibility, histocompatibility and 
Table 1. Classification of PNS injuries by Seddon and Sunderland (adapted).$^{[1,14-16]}$

\begin{tabular}{|c|c|c|c|}
\hline Seddon classification & Sunderland classification & Pathology & Prognosis \\
\hline Neurapraxia & First degree & No axon loss & $\begin{array}{l}\text { Spontaneous recovery time between } \\
\text { hours up to a few months }\end{array}$ \\
\hline \multirow[t]{3}{*}{ Axonotmesis } & Second degree & Axon loss & $\begin{array}{l}\text { Spontaneous recovery can be achieved without } \\
\text { surgery depending on the distance to muscle }\end{array}$ \\
\hline & Third degree & $2^{\text {nd }}$ degree + Disruption of the endoneurial tubes & $\begin{array}{l}\text { Spontaneous recovery is poor due to axonal } \\
\text { misdirection. Surgical intervention may be required }\end{array}$ \\
\hline & Fourth degree & $3^{\text {rd }}$ degree + Disruption of the perineurium & $\begin{array}{l}\text { Spontaneous recovery is worse than } 3^{\text {rd }} \text { degree. } \\
\text { Surgery is more often required. }\end{array}$ \\
\hline Neurotmesis & Fifth degree & $\begin{array}{l}\text { Entire nerve disruption. Connective tissue } \\
\text { components of the nerve severed. }\end{array}$ & Recovery depends on surgical intervention \\
\hline
\end{tabular}

mechanical compatibility. The first one requires that blood should not undergo hemolysis or damage of its components that could result in coagulation and formation of thrombus, when in contact with the NGC. The second aspect demands that no toxic side effects should arise from the device that
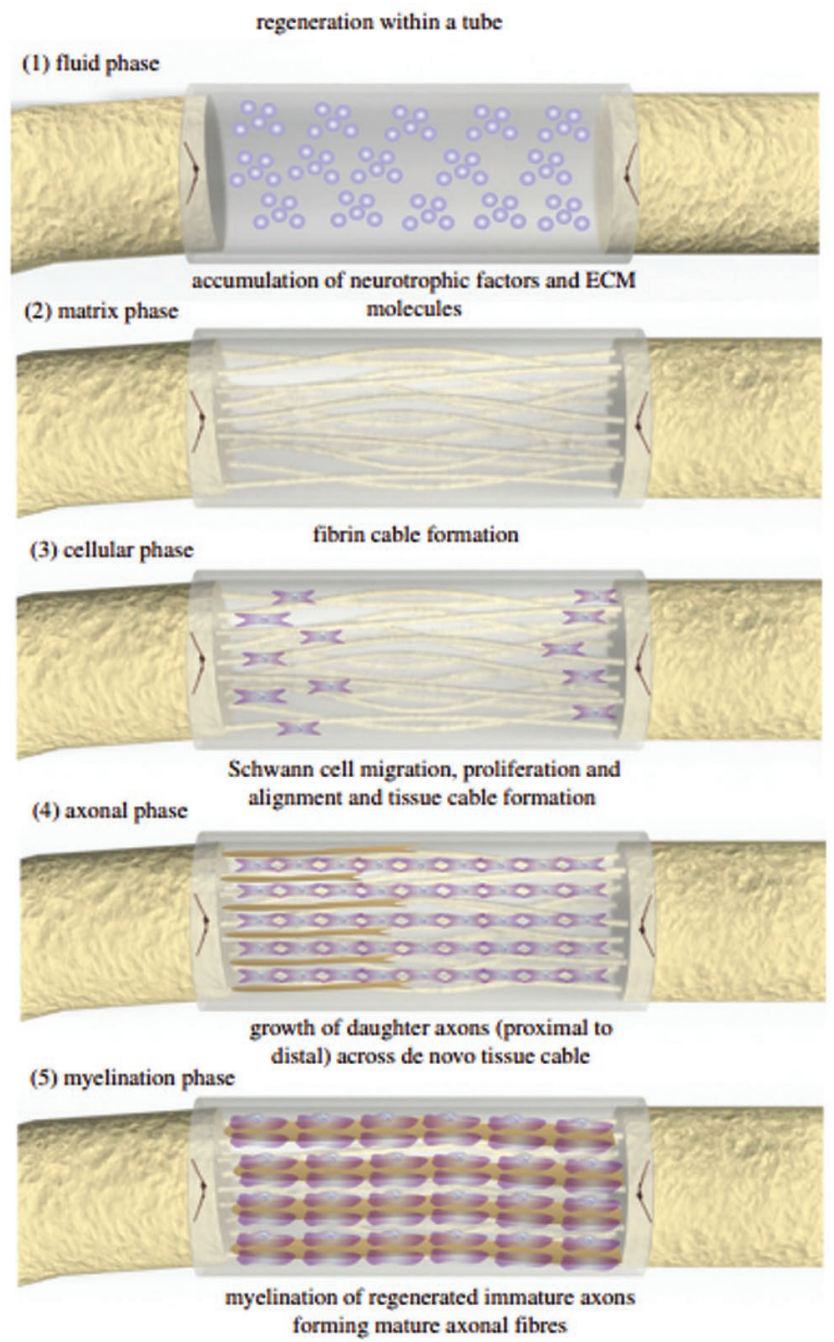

Figure 1. Nerve regeneration within a hollow NGC. Reproduced with permission. ${ }^{[2]}$ Copyright 2012, The Royal Society. could contaminate surrounding tissue. The last one concerns the mechanical properties of the NGC, which should match the same properties of nerve tissue. ${ }^{[26]}$ As referred above, a NGC should provide a pathway for nerve regeneration, resist tearing from sutures and provide a mechanically stable architecture for the new tissue. ${ }^{[27]}$ Therefore it should remain intact during the first stages of regeneration. The degradation should start after some time, depending on the size and type of injury, in a very slow way with no swelling, constriction or foreign body response. ${ }^{[28]}$ The NGC should be semi-permeable to allow the diffusion of nutrients, oxygen, and growth factors to the inside of the tube and, at the same time, it should allow the exclusion of waste products to the outside of the tube. ${ }^{[21,29,30]}$ Some researchers believe that the material used has to be permeable to a molecular weight of up to $50 \mathrm{kDa} .{ }^{[21]}$ Other aspects that have to be considered are both the diffusion of inflammatory cells to the inside of the tube, which has to be avoided, and the diffusion of growth factors to the outside of the tube. Since the permeability of the material is directly related to the porosity, it is reported that ideally the pore size should be between $5-30 \mu \mathrm{m}$, with preferred values in the range of $10-20 \mu \mathrm{m} .{ }^{[31]}$ With pores smaller than $5 \mu \mathrm{m}$, cells and new tissue are unable to cross and above $30 \mu \mathrm{m}$ the material is too permeable to inflammatory cells, which will compromise nerve regeneration. ${ }^{26]}$ It is important to mention that some of the fluid inside the tube should diffuse to the outside, in order to avoid a pressure increase inside the conduit due to fluid retention. Since the main function of the NGC is to provide a pathway for nerve regeneration, it has to present proper biomechanical properties for this application. ${ }^{[26]}$ A NGC should be smooth and flexible to avoid new fiber compression, but at the same time, it also requires some stiffness, as the conduit has to be resistant to bending without the risk of collapsing with shape loss. ${ }^{[23,29]} \mathrm{Nev}$ ertheless, a conduit that is too stiff can easily cause distortion and one which is too flexible can fail to support regeneration. ${ }^{[28]}$ Due to these facts, the fine balance between these two properties is required. The Young modulus of a NGC should also be similar to those of the nerves, in order to ensure the necessary resistance to the common in vivo physiological loads $(65-155 \mathrm{~N}$ for ulnar and $73-220 \mathrm{~N}$ for median nerves). ${ }^{[28]}$ These properties are mostly dependent on the chosen material, dimensions, thickness, diameter of the lumen and lumen fibers, as will be described in the following sections. The surface properties of the tubes need to be evaluated, since during the formation of 
Table 2. Most common growth factors used in nerve guide conduits. ${ }^{[19,31,33]}$

\begin{tabular}{lr}
\hline Growth Factor & Function \\
\hline $\begin{array}{l}\text { Nerve growth factor } \\
\text { (NGF) }\end{array}$ & $\begin{array}{r}\text { Involved in the survival of the sensory nerve cell } \\
\text { bodies and outgrowth of their neurites. }\end{array}$ \\
$\begin{array}{l}\text { Glial Growth factor } \\
\text { (GGF) }\end{array}$ & $\begin{array}{r}\text { Induces schwann cell motility and proliferation. Helps } \\
\text { improving the survival of motor/sensory neurons. }\end{array}$ \\
Fibroblast growth & Stimulates mitogenesis which increases \\
factor (FGF) & cell growth and regeneration. \\
Glial cell-derived & Improve motor/sensory neuron survival, neurite \\
neurotrophic factor & outgrowth and schwann cell migration. \\
(GDNF) & \\
Neurotrophin -3 & Restoration of sensory/motor conduction velocity.
\end{tabular}

the new tissue, this will interact with the surface of the conduit. A longitudinal texture has been reported as ideal to help the alignment of the Schwann cells. ${ }^{[32]}$ As nerve gaps differ in size and neurons have different diameters and sizes, the length and lumen dimensions of a NGC should be easily adjustable to the specific nerve type to be recovered.

Another approach that has been used in the design of NGC is the incorporation of luminal fillers, either growth factors or accessory cells, in the tube as a means of improving the efficiency of reconstruction for both small and large gaps. Table 2 shows the most common growth factors and their functions in nerve regeneration.

Schwann cells also represent an attractive class of luminal fillers due to their key role in the nerve regeneration process. Nevertheless, other accessory cells like bone-marrow stromal cells, ectomesenchymal stem cells and fibroblasts can be used to enhance the nerve regeneration process. ${ }^{[11]}$

The incorporation of these cells and growth factors in nerve guide conduits can be performed in different ways, namely: (i) use of a matrix for the delivery of growth factors or accessory cells. This matrix will provide support and guidance for regenerating axons, control the release of growth factors avoiding an enzymatic breakdown and growth of supportive cells. However, these growth factors and/or accessory cells are incorporated in a hydrogel that can be too dense enabling cell growth; (ii) use of an affinity-based system for the delivery of growth factors or accessory cells; (iii) impregnating the NGC wall with accessory cells or growth factors via crosslinking or immobilization (diffusion-based systems). By crosslinking the growth factors, there is no need to use hydrogels, but not all crosslinking preparations are biodegradable. Crosslinking of different types of growth factors is also possible; (iv) direct culturing of accessory cells on the NGC wall which results in empty lumens not compromising the growth of new axons. Unfortunately the absence of supportive cells at the surface of the lumen can be a disadvantage; (v) using microspheres to delivery growth factors or accessory cells to the NGC lumen providing multiple unit dosage but there are many limitations in what concerns the microencapsulation technology and growth factor stability. Other strategies involve the use of genetically modified cells which arises safety issues due to viral vectors or the application of mechanical devices that allow the delivery of multiple proteins simultaneously.
However, non-biodegradable systems imply further surgical removal. ${ }^{[11,34,35]}$

There are also some technical requirements that should be taken into account when preparing a NGC. It should be able to be sutured onto the nerve stumps and it should be able to bear surgical handling. NGC should exhibit a long-term storage and has to be sterilizable, as all medical devices that are created for implantation purposes. ${ }^{[36]}$ Also, to facilitate its implantation, transparent NGC are preferred.

\section{Peripheral Nerve Regeneration: Strategies}

In the search for an efficient method to bridge nerve gaps with success, a vast portfolio of materials and different approaches has been proposed. In this section, the most common ones, as well as their advantages and disadvantages are going to be discussed.

\subsection{Nerve Autograft}

For the last 50 years, nerve autograft has been considered the gold standard for bridging nerve gaps. ${ }^{[21]}$ Autografting was reported for the first time between 1870 and 1900, and Millesi was the first researcher demonstrating the benefits of this technique using animal studies. ${ }^{[29]}$ The technique consists in harvesting a nerve from another site of the body, which is then used to connect the two nerve stumps and align the fibers to allow functional recovery of the injured nerve. The most common nerve used in this approach is the sural nerve, taken from the back outer ankle. ${ }^{[16,29]}$ The factors that affect the choice of the most suitable nerve to harvest is related to the location of the nerve to be repaired, size and diameter of the nerve gap and associated donor-site morbidity. ${ }^{[37]}$

The use of nerve autografts bring some advantages because they act like immunogenically inert scaffolds that have the ability to provide the appropriate neurotrophic factors and Schwann cells. ${ }^{[29,37,38]}$ However, this technique also has many disadvantages, such as: donor site morbidity due to harvesting; donor site mismatch; limited supply; requirement of a second surgery; possibility of painful neuroma formation and scarring; and loss of function, especially in injuries of the motor nerves. ${ }^{[21,23,29,38,39]}$ Additionally, the use of nerve autografts is limited to nerve gaps with lengths of approximately $5 \mathrm{~cm}$.

\subsection{Nerve Allograft}

The use of nerve allografts in the regeneration of nerves was reported for the first time in 1885, by Albert Einige. This technique consists of harvesting the missing nerve material from humans cadavers, followed by the implantation and suture to the injured nerve. ${ }^{[40]}$ Nowadays, allografts are mostly used for segmental nerve injuries. ${ }^{[16]}$ They can be used fresh, or pretreated by techniques such as freezing, freeze-drying, freezethawing, pre-degeneration and chemical treatments with or without immunosuppressants. ${ }^{[38]}$ 
The choice of using a nerve allograft always comes after some limitation (e.g., length) of nerve autografts. One of the advantages of using these materials is related to the fact that there is an abundant supply of donor nerves. ${ }^{[37]}$

However, many disadvantages are also associated to this technique, being the most important the occurrence of an undesirable immune response, and the need for systemic immunosuppression to prevent rejection and potential immunogenicity. ${ }^{[41]}$ At the same time, the patient is really prone to infections, disease transmission risk and in the most severe cases, even tumor formation. ${ }^{[16]}$ Immunosuppression can be avoided when nerve allografts are decellularised. ${ }^{[42]} \mathrm{A}$ commercial product with these characteristics has already been commercialized under the tradename of AxoGen. This device acts as a scaffold whose structure is provided by the extracellular matrix. ${ }^{[16]}$

FDA approved a commercial product called Avance, made of cadaveric material, which does not need immunosuppression. ${ }^{[36]}$ This material has all the advantages associated with the nerve allografts, and allows the choice of the type of nerve needed. However, over time, immunosuppression may be required. ${ }^{[36]}$

Due to the problems listed above concerning nerve autografts and allografts, new alternatives using different materials need to be investigated. Natural materials, biopolymers and synthetic polymers have been used to produce NGC and tested in order to enhance nerve regeneration. The following sections describe the materials that have been used, their structure, formulations and clinical trials results.

\subsection{Natural Materials for Nerve Conduits}

\subsubsection{Blood Vessels}

Blood vessels, such as arteries and veins, have been used to bridge nerve gaps since the first years of the $19^{\text {th }}$ century. The use of arteries was first reported in 1891 with good results, but the lack of suitable donor vessels made this technique fall into unpopularity and its clinical implementation has never occurred. ${ }^{[43]}$

Veins began being used in 1909, and since then many experiments were carried out. One of the most interesting conclusions was that the application of veins as NGC was more successful when nerve slices were used to seed its lumen. ${ }^{[43]}$ This interposition was considered a practical and reliable procedure for nerve gaps between 2 and $4.5 \mathrm{~cm} .{ }^{[43]}$

One of the main advantages in using veins is that they are extremely abundant and induce less donor-site morbidity. ${ }^{[38]}$ However, the possibility of collapsing due to their thin walls, turn veins a non-recommended tissue for gap bridging. ${ }^{[44]}$

\subsubsection{Muscle}

Skeletal muscle in nerve repair applications was first reported in $1940 .{ }^{[45]}$ Studies demonstrated that fresh and denatured conduits made from muscle could lead to regeneration of nervous tissue. As to the advantages of its use, it has extracellular matrix components and longitudinally oriented basal lamina. These factors are extremely useful for enhancing nerve regeneration as this microenvironment helps to promote cell adhesion. ${ }^{[38]}$ Also, it can be noted that there are numerous donor sites from which muscle tissue can be harvested. ${ }^{[43]}$ However, this fact represents a disadvantage because a harvesting procedure has to be performed. Moreover, using muscle has its risks, as some nerve fibers may grow out of the muscle tissue while the regeneration process is occurring. ${ }^{[43]}$

\subsubsection{Tendon}

Tendon from rat tail has already been used for nerve regeneration. In the most known experiment, a $10 \mathrm{~mm}$ nerve gap was bridged. ${ }^{[46]}$ As the rat tail tendon has extracellular matrix components and also a longitudinal arrangement of collagen, it constitutes a good path for cells to adhere to during nerve regeneration. ${ }^{[43]}$ In terms of morphometric and functional evaluation, the results obtained by autografting are quite similar to muscle graft. Unlimited source of graft material, as well as limited loss of function, are the main advantages of these tissues for nerve bridging. ${ }^{[38]}$

Reports concerning the use of natural materials in nerve regeneration are summarized in Table 3.

\subsection{Natural Polymers}

Following nerve allografts, natural polymers were seen as reliable alternative materials to construct nerve autografts. ${ }^{[30]}$ The most common naturally-derived polymers used in nerve regeneration are collagen, chitosan and alginate.

\subsubsection{Collagen}

Collagen is a structural protein of connective tissues in humans and animals and the major component of extracellular matrix (Figure 2).

Due to this fact, it has been used in implants as wound dressings and artificial skin. ${ }^{[28]}$ It is a natural biodegradable material with high biocompatibility, low antigenicity, which is known to promote neurite outgrowth, nerve regeneration and helps to maintain biological functions of the cells. ${ }^{[28,30,59,60]}$

This material has been used as NGC since 1990s, adopting different forms. FDA already approved some nerve guide devices using Type I Collagen. Table 4 summarizes their features.

These include fibers inserted inside the conduit's lumen to function as fillers and hydrogel formulations to deliver cells, drugs or growth factors. ${ }^{[28]}$

Some studies have also shown that collagen filaments incorporated in NGC made with biodegradable materials, help to guide the new nerve fibers as they improve permeability and surface area exposed to the surrounding tissue. ${ }^{[59]}$

As collagen is a natural polymer, it presents poor mechanical strength, high water uptake and fast degradation, which 
www.MaterialsViews.com

Table 3. Summary of the natural materials used in NGC, and main results obtained.

\begin{tabular}{|c|c|c|c|c|c|c|}
\hline Year & Material & Nerve & Gap (mm) & Animal & Results & Ref \\
\hline 1982 & Vein & Sciatic & 10 & Rat & Conduction restored after 4 months of surgery & [47] \\
\hline 1984 & Vein & Sciatic & 25 & Rat & Satisfactory results with minimal scar tissue formation & [48] \\
\hline 1986 & Artery & Peroneal & 5 & Rat & Growth of a minority of axons & [49] \\
\hline 1986 & Muscle & Sciatic & 40 & Rat and Rabbit & Satisfatory limb function recovery & [50] \\
\hline 1986 & Vein & Femoral & 14 and 2 & Rabbit & Smaller gap had better remyelination comparing with the longer one & [51] \\
\hline 1988 & Vein & Sciatic & 5 & Rat & Nerve vein graft conduction velocity similar to autogenous nerve graft & [52] \\
\hline 1989 & Vein & Peroneal & 10 & Rat & Vein graft shower similar pattern of nerve regeneration as nerve graft & [53] \\
\hline 1992 & Aortic & Tibial & 10 & Rat & Preferential growth toward the distal nerve was observed & [54] \\
\hline 1992 & Muscle & Peroneal & 50 & Rat & Muscle graft did not lead to reliable recovery & [55] \\
\hline 1993 & Vein & Sciatic & 10 & Rat & $\begin{array}{l}\text { Compared with polyethylene nerve conduit, vein graft showed accelerated } \\
\text { rate of nerve regeneration and significantly earlier myelination. }\end{array}$ & [56] \\
\hline 1994 & Vein & Sciatic & 10 & Rat & Small regenerated axons & [57] \\
\hline 2007 & Muscle+Vein & Median & 10 & Dog & $\begin{array}{l}\text { Fresh and predegenerated skeletal muscle present similar results after } \\
\qquad 1 \text { month regarding to integrity }\end{array}$ & [58] \\
\hline
\end{tabular}

are undesirable characteristics in nerve regeneration. Indeed, the structural integrity is compromised and the swelling can compress the new nerve tissue as it is growing. ${ }^{[30]}$ To overcome such disadvantages, some techniques, like solution casting and freeze-drying, are being performed to achieve the required mechanical strength and porosity. ${ }^{[30]}$ The mechanical strength can also be improved by crosslinking collagen between amine groups, which provides structural stability to the NGC. ${ }^{[2]}$ Among the techniques used for preparation of collagen nerve conduits, the most reported ones include injection molding and dip-coating, extrusion, electrospinning, freeze drying followed by lyophilization and crosslinking due to microwave radiation. ${ }^{[2,27]}$ Table 5 presents some of the works where collagen was used as NC.

\subsubsection{Chitosan}

Chitosan (Figure 3) is a cationic biopolymer obtained from the alkaline deacetylation of chitin, which is the most abundant natural polymer after cellulose. ${ }^{69,70]}$

Over the years, chitosan has been widely used in several biomedical applications, ${ }^{[70-75]}$ mainly because of its promising intrinsic properties. Among them, it is possible to mention:
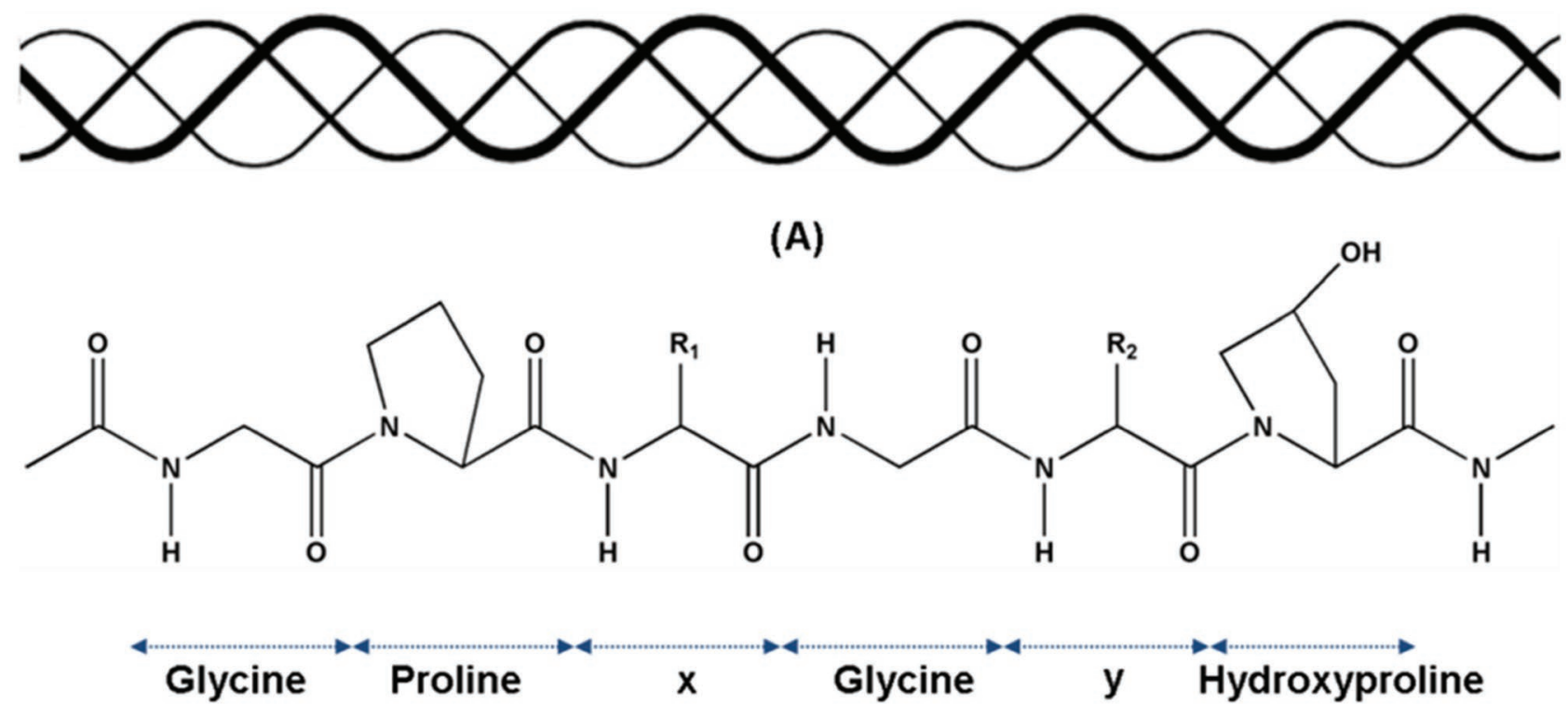

(B)

Figure 2. Chemical structure of collagen type I. (A) secondary left handed helix and tertiary right handed triple-helix structure, (B) primary amino acid sequence). Reproduced with permission. ${ }^{[61]}$ Copyright 2011, Springer. 
Table 4. Type I Collagen devices approved by FDA for peripheral nerve regeneration. ${ }^{[36]}$

\begin{tabular}{lccccc}
\hline Type of device & Product Name & Degradation & Diameter & Length & Company \\
\hline Nerve guide & NeuraGen & $36-48$ months & $1.5-7 \mathrm{~mm}$ & $2-3 \mathrm{~cm}$ & Integra Life Sciences Corp. \\
Nerve guide & Neuroflex & $4-8$ months & $2-6 \mathrm{~mm}$ & $2.5 \mathrm{~cm}$ & Collagen Matrix Inc. \\
Nerve guide & NeuroMatrix & $4-8$ months & $2-6 \mathrm{~mm}$ & $2.5 \mathrm{~cm}$ & Collagen Matrix Inc. \\
Nerve cuff/protectant wrap & NeuraWrap & $36-48$ months & $3-10 \mathrm{~mm}$ & $2-4 \mathrm{~cm}$ & Integra Life Sciences Corp. \\
Nerve cuff/protectant wrap & NeuroMend & $4-8$ months & $4-12 \mathrm{~mm}$ & $2.5-5 \mathrm{~cm}$ & Collagen Matrix Inc. \\
\hline
\end{tabular}

biocompatibility, ${ }^{[39,75,76]}$ biodegradability, ${ }^{[69,75]}$ low toxicity and non-immunogenicity, ${ }^{[69,75,76]}$ low cost and large availability. ${ }^{[75,76]}$

Very recently, chitosan started to be used in the fabrication of NGC for peripheral nerve regeneration, with some success. ${ }^{[74]}$ The good results obtained might be due to the favorable interaction of chitosan with biological environments, namely the promotion of cell attachment, adhesion, differentiation, and survival, ability to create a good pathway for neurite outgrowth and ability to inhibit the scarred tissue formation. ${ }^{[39,75,77]}$

Unfortunately, some structural properties of this biopolymer are not suitable for the construction of NGC, its mechanical strength being the most critical issue. As it presents low mechanical strength under physiological conditions, the capability to maintain a certain structure, needed to guide the new fibers, is seriously compromised. ${ }^{[71,73,75]}$ Usually, chitosan is subjected to a crosslinking reaction with, for instance, genipin, ${ }^{[78]}$ to compensate the lack of mechanical strength. This formulation was already tested in many biomedical applications such as drug carriers and in the encapsulation of biological products and living cells. ${ }^{[78]}$ The addition of chitin powder to chitosan solution has also been tested to increase mechanical strength. ${ }^{[79]}$

Along with mechanical strength, porosity is also a property which has to be optimized in order to achieve the adequate value. ${ }^{[78]}$ Porosity is related to the fabrication procedure of the material to be implanted. The most common techniques used are cast molding, with molds made of stainless steel, and knitting techniques combined with lyophilization have been used. ${ }^{[39,75,79]}$

Table 6 presents some studies regarding the use of chitosan in nerve regeneration, as well as their main results, performed since the middle 2000s.

\subsubsection{Poly (3-hydroxy butyrate) (PHB) and Poly(3-hydroxybutyrate- co-hydroxyvalerate) (PHBV)}

Poly-3-hydroxbutyrate (PHB) is a bio-absorbable polymeric material that is synthesized by microorganisms that use determined substrates as carbon sources, under conditions of limiting nutrients. ${ }^{[83]}$ It can be produced from fermentation followed by solvent extraction from bacterial cultures and carbon substrates. ${ }^{[84]}$ Its copolymer with 3-hydroxyvalerate, poly(3hydroxybutyrate-co-hydroxyvalerate) (PHBV), is more flexible and easier to process when compared with PHB. PHB is usually molded into a sheet made with aligned fibers, and at the end of the 1990s the first attempts in using this material for peripheral nerve regeneration were reported showing effect on helping regeneration of axons. ${ }^{[85]}$ PHB is non-antigenic and presents good tensile strength, but its degradation lasts at least 24 to 30 months till all polymer is resorbed. ${ }^{[84]}$ Some years later, a comparative study between the performance of PHB with epineural suturing was carried out in the median and/or ulnar nerve at the wrist/forearm level. The results suggested better recovery with PHB than with epineural suturing. ${ }^{[83]}$ The effect of blending PHB and PHBV has also been studied. The resulting material is easier to handle as its melting point decreases. After the blending, the scaffold was obtained by electrospinning. Satisfactory results were obtained in this study as good Schwann cells proliferation was observed, which increased with the addition of collagen to the scaffold. ${ }^{[86]}$ More recently, Biazar et al. have been performing studies using PHBV as the unique material for the preparation of nerve guide tubes, achieving interesting results in what concerns mechanical properties. Also, as the nerve guide was micro patterned, improvement in adhesion of Schwann cells was observed. ${ }^{[41]}$ Later, the same author, crosslinked PHBV with gelatin, and the resulting material

Table 5. NGC made with collagen submitted to in vivo tests.

\begin{tabular}{|c|c|c|c|c|c|c|}
\hline Year & Material & Nerve & Gap $(\mathrm{mm})$ & Animal & Results & Ref \\
\hline 1983 & Collagen & Radial & 8 & Cat & Reinnervation of sensory structures & [62] \\
\hline 1990 & Collagen-PGA & Peroneal & 0.5 & Rat & Axonal regeneration equal to sutured autografts & {$[63]$} \\
\hline 1991 & Collagen & Sciatic & 4 & Rat & Nerve regeneration similar to nerve autograft & {$[64]$} \\
\hline 2009 & Collagen & Peroneal & 10 & Rat & Regeneration of motor axons with no noticeable foreign body reaction & {$[59]$} \\
\hline 2010 & Collagen & Peroneal & 30 & Dog & Functional recovery of the regenerated nerve & [65] \\
\hline 2013 & Collagen & Median & $10-20$ & Human & 8 in 9 patients achieved functional recovery & {$[66]$} \\
\hline 2013 & Collagen & Digital & $\leq 26$ & Human & Useful to span digital nerve defects up to $2.6 \mathrm{~cm}$ & [67] \\
\hline 2014 & Collagen-Collagen fibers & Sciatic & - & Rat & Nerve regeneration similar to nerve autograft & {$[60]$} \\
\hline 2014 & Collagen & Sciatic & 10 & Rat & Study of the influence of the conduit diameter for motor recovery & [68] \\
\hline
\end{tabular}




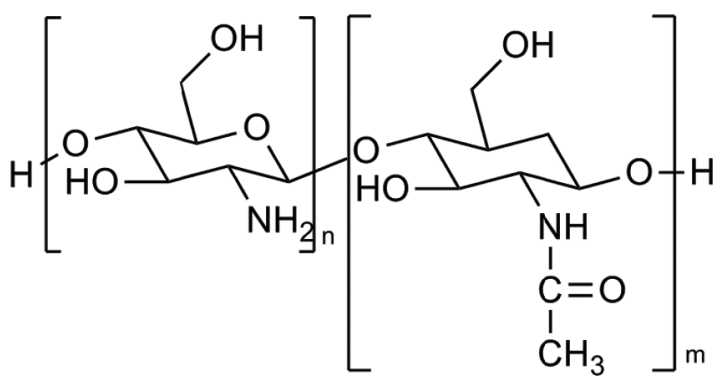

Figure 3. Chitosan structure

showed improved cellular adhesion in comparison with PHBV alone. The tube was used to bridge a gap with $30 \mathrm{~mm}$ in the sciatic nerve of a rat. After four months, restoration of the nerve and myelated nerve fibers were observed. ${ }^{[41]}$ More recently a study has been reported where PHBV was crosslinked with laminin, proving that cell adhesion on its surface was improved compared with the neat PHBV. ${ }^{[87]}$ All these results show that most specifically $\mathrm{PHBV}$ is a promising material for peripheral nerve regeneration due to good mechanical properties, cellular interaction, and also the possibility to control the degradation rate of its constructs.

\subsubsection{Alginate}

Alginate is a linear polysaccharide copolymer of (1-4)-linked $\beta$-D-mannuronic acid (M) and $\alpha$-L-guluronic acid $(\mathrm{G})$, extracted from brown seaweed. ${ }^{[4]}$ It is biocompatible, biodegradable, sterilizable without degradation, and, very importantly, its physical and rheological properties can be easily modified by varying the monomers ( $\mathrm{G}$ and $\mathrm{M}$ ) ratio and molecular weight of the polymer chain..$^{[4,88]}$ Since the past decade, the interest in alginate for biomedical applications has increased significantly due to its good cell compatibility. ${ }^{[89]}$ Alginate based hydrogels have been used as covers for diabetes treatment and hemophilia, detoxification, transplanted pancreas or liver cells, and as bridging materials for both spinal cord and nerve repair. ${ }^{[4,90]}$ In what concerns the nerve regeneration, the compatibility of this biopolymer with Schwann cells, neurotrophic factors and stem cells is a very interesting and the most decisive characteristic. ${ }^{[4,90,91]}$

In peripheral nerve regeneration, alginate is usually used as a gel which is inserted in the conduit lumen to guide the new nerve fibers. However, it is reported in literature that the regeneration of nerve tissue requires that some quantity of gel has to degrade, in order to open space in the lumen. ${ }^{[91]}$ This gel usually results from the crosslinking of alginate with calcium ions. ${ }^{[91]}$ The gel degradation starts with the diffusion on the calcium ions from alginate, allowing the slow loss of crosslinking of the alginate gel. The resulting products are immunologically inert and are not digested by mammalian cells. [90]

Alginate gels have been tested both in vitro and in vivo for peripheral nerve regeneration purposes, but contradictory results were obtained. In vitro tests showed a negative influence of alginate on cell proliferation. Unexpectedly, in vivo tests showed the opposite. A sciatic nerve gap with $7 \mathrm{~mm}$ in rats and a sciatic nerve gap with $50 \mathrm{~mm}$ in cats were successfully bridged with alginate foams, leading to promising results. ${ }^{[28]}$ Because of this paradox, and due to ethical issues, alginates are not widely used materials for peripheral nerve regeneration. More recently, the attempt to crosslink alginate with chitosan has been reported, and interesting results were achieved. ${ }^{[89]}$

Other materials such as hyaluronic acid, natural silk, silk fibroin and keratin have also been tested, but not as intensively as the former ones. These materials lack some important properties, namely mechanical stability. Consequently, the only way to use them is by chemical modifications via crosslinking or by incorporation in other natural or synthetic biomaterials. ${ }^{[28]}$

\subsection{Synthetic Polymers}

During the last years, enormous efforts have been made to create NGC based on synthetic polymers. Typically, these materials can be classified as non-degradable and degradable.

Table 6. Chitosan membranes and NGC tested for nerve regeneration in vivo.

\begin{tabular}{|c|c|c|c|c|c|c|}
\hline Year & Material & Nerve & Gap (mm) & Animal & Resultados & Ref \\
\hline 2004 & Chitosan-chitin powder & Sciatic & 8 & Rat & Compatible with the surround tissue in vivo & [79] \\
\hline 2005 & Chitosan-neurosteroids & Facial & 10 & Rabbit & $\begin{array}{l}\text { Regeneration of the nerve fibers. Faster regeneration when } \\
\text { using the neurosteroids in vivo }\end{array}$ & [80] \\
\hline 2005 & $\begin{array}{l}\text { Chitosan-Filaments } \\
\text { of PGA }\end{array}$ & Sciatic & 30 & Dog & Restoration of nerve continuity and functional recovery & [39] \\
\hline 2009 & Chitosan-GDNF & Sciatic & 10 & Rat & Axon area and myelination higher than chitosan tube (control) & [69] \\
\hline 2010 & $\begin{array}{l}\text { Cross-linked carboxy- } \\
\text { methyl chitosan }\end{array}$ & Sciatic & 10 & Rat & $\begin{array}{l}\text { Myelin sheath similar to nerve autografts and higher fiber } \\
\text { density compared to chitosan tube }\end{array}$ & [70] \\
\hline 2013 & $\begin{array}{l}\text { Chitosan with varying } \\
\text { degrees of acetylation }\end{array}$ & Sciatic & 10 & Rat & Poor mechanical properties and low stability & [73] \\
\hline 2013 & $\begin{array}{l}\text { Collagen-Chitosan with } \\
\text { RGD }\end{array}$ & Sciatic & 15 & Rat & $\begin{array}{l}\text { Faster regeneration with RGD compared with } \\
\text { collagen-chitosan tubes }\end{array}$ & [81] \\
\hline 2015 & Chitosan & Phrenic & 15 & Dog & Functional recovery was not totally achieved & [82] \\
\hline
\end{tabular}




\subsubsection{Non-Biodegradable Synthetic Polymers}

While trying natural polymers, researchers also focused their interest on non-biodegradable polymeric materials to be used in nerve regeneration due to their superior mechanical properties. Good results were achieved for small gaps, but in many cases the conduits had to be removed due to immunologic response. The next topic presents the most used non-degradable polymeric materials for nerve regeneration purposes and also the new trends in using these materials.

Silicone: Since $1960 \mathrm{~s}$, silicone has been studied as material for NGC in peripheral nerve regeneration. It was one of the first synthetic materials to be used in these applications due to its elastic properties and inertness. ${ }^{[28]}$ It is non-biodegradable and non- permeable to large molecules.

The first researcher to present a successful case of recovery from an injury using silicone was Merle. ${ }^{[2]}$ Some years later, Chen, doped silicone tubes with laminin, collagen and fibronectin gels, concluding that better results than the nondoped silicone tube can be achieved. ${ }^{[93]}$ Lundborg, in turn, concluded that silicone tubes gave better regeneration results in gaps smaller than $5 \mathrm{~mm} .{ }^{[94-97]}$ This was confirmed after another study where a $8 \mathrm{~mm}$ gap in the peroneal nerve of the rat was bridged with a silicone tube showing the presence of new axons, although some of them not myelinated. ${ }^{[98]}$ However, many works in rats also reported the formation of scarred tissue, compression of the new axons or even no regeneration at all. ${ }^{[9-101]}$

Moreover, researchers also refer that in some patients, silicone tubes had to be removed because of loss of nerve function due to irritation at the implantation site. As this material is non-biodegradable, a chronic inflammation associated to excessive scarred tissue formation can occur during time, in some cases, after one week. ${ }^{[24]}$ Contradictory results have been more recently reported in histomorphometrical and immunohistochemical assessments, which supported that no excess of scarred tissue was formed and axons can regenerate within a silicone tube. ${ }^{[102]}$ Ikeguchi et al. implanted negative-charged carbon ions in the inner surface of a silicone tube, claiming that axonal regeneration was improved. ${ }^{[103]}$ Unfortunately, none of these recent works gives further information concerning the consequences that this type of conduits could evoke a long time after implantation.

Expanded poly(tetrafluorethylene) (ePTFE): ePTFE was discovered in the 1970s and it's chemically identical to PTFE but, after processing, it presents billions of small pores. This porous structure can be obtained without the use of soluble fillers, foaming agents or other chemical additives. ${ }^{[104]}$

It is used to make lightweight, waterproof and breathable fabrics, micro-porous membranes, microwave carriers, industrial sealants and high-tensile fabrics and cords and medical tubes and implants. ${ }^{[104]}$

For peripheral nerve regeneration, a product made from ePTFE is commercialized under the tradename of Gore-Tex. The main conclusions taken from in vivo trials in humans were that small gaps in the lower arm $(15-40 \mathrm{~mm})$ were successfully bridged, but longer defects (till $60 \mathrm{~mm}$ ) could not recover and useful reinnervation was only verified in $13.3 \%$ from a population of 43 patients. ${ }^{[29]}$
In another trial, Gore-Tex was used in seven patients with nerve defects $(<3 \mathrm{~mm})$ in the inferior alveolar nerve, and only two of them revealed some return of sensation. ${ }^{[104]}$ Also, this product causes an excess of scarred tissue formation, compression of the new fibers and severe immunologic responses from the host body. Nowadays, and for these reasons, these materials are lacking the interest from the medical field.

Polypyrrole (Ppy): Ppy is a conductive polymer which is commonly used in advanced materials such as sensors, solar cells, water treatment materials, among others. ${ }^{[105]}$ It has been object of interest for peripheral nerve regeneration in recent years due to the positive responses induced in cells by electric stimulation. ${ }^{[106]}$ Among the many advantages of using this material there is the fact that it can support cell adhesion and has a good biocompatibility and no evidence of toxicity. ${ }^{[107]}$ The first time that neurite outgrowth from PC12 cells in contact with a film of Ppy was reported was in 1997 proving that conductive polymers could be useful for nerve regeneration applications. ${ }^{[108]}$ After these findings, researchers have tried to incorporate new features to Ppy based NGC, such as the incorporation of adhesive cells. Also, changing the topography of these materials has proved to help in the regeneration of new axons due to guidance providence. ${ }^{[109]}$ Unfortunately, the use of Ppy brings some disadvantages, namely those related with its slow degradation rate and poor solubility. ${ }^{[10]}$ For that reason, Ppy has been incorporated in composite materials as a way to overcome its drawbacks. Using emulsion polymerization, Xu et al. prepared Ppy/ PDLLA conductive composites and it was found that the materials were able to support neurite regrowth in a similar way to that of autologous grafting. ${ }^{[110]}$ More recently, nerve guide tubes based on PVA/Ppy were also studied. The tubes were prepared using a casting technique and molded in a silicone tube. A satisfactory number of regenerated nerve fibers was achieved although better results were obtained by a conduit based on PVA loaded with multi-wall carbon nanotubes (MWCNT) seeded with Mesenchymal stem cells (MSCs). ${ }^{[111]}$ In conclusion, conductive polymers have demonstrated to be promising materials for peripheral nerve regeneration, when blended with other polymers with more desirable solubility, mechanical and degradation properties.

\subsubsection{Biodegradable Polymers}

Due to the problems caused by non-biodegradable polymers, their biodegradable counterparts have started to be more popular for peripheral nerve regeneration. These materials have the ability to fully degrade in vivo, which leads to a new approach for this application: by the end of the regeneration, the conduit should be gone completely and with that avoid immune response from the body. Many biodegradable materials were tested, but in this section only poly(glycolic acid) (PGA), poly(lactic acid-co-glycolic acid) (PLGA), poly( $\varepsilon$-caprolactone) (PCL), and poly(DL-lactic acid -co- $\varepsilon$-caprolactone) (P(DLLACo-CL)) will be presented, as they are those with more clinical trials and with FDA approved products.

PGA: PGA is an aliphatic polyester known in the biomedical field as a suture material for wound closure. It has been used for a long time in this application because it can be absorbed by 
the human body within 90 days after implantation, through an hydrolysis mechanism. ${ }^{[112]}$ Due to its good biological properties, the interest in producing NGC from this material has increased substantially.

PGA was first used as a NGC in 1990, by Mackinnon and Dellon, and the results were similar to those obtained from nerve autografting. ${ }^{[113]}$

Although several works report good results, others refer that PGA alone has a too fast degradation rate, which can be undesirable for larger nerve gaps. Another problem concerns the technique used to fabricate the conduit. When extrusion was used, the surface of PGA conduits presented poor quality. ${ }^{[43]}$ Moreover, while it degrades, the products that are released have an acidic nature, leading to the decrease of the $\mathrm{pH}$ at the site of implantation that can trigger the immune response.

A new approach was then adopted and involved the use of PGA, not as the core material of the nerve conduit, but as filler. ${ }^{[14]}$ Good results came from these works, which lead researchers to conclude that PGA is a good material for nerve regeneration, especially when combined with other materials, of which chitosan and collagen are examples. ${ }^{[115-118]}$

In 1999, the first commercial product made from PGA was approved by the FDA under the tradename of Neurotube, which is indicated for bridging gaps between $2-4 \mathrm{~cm}$. It presents a diameter of $2.3-8 \mathrm{~mm}$ and degrades within approximately 3 months. ${ }^{[36]}$

PLGA: PLGA is an aliphatic copolyester made from glycolic and lactic acid that has FDA approval and has been used as a suture material throughout the years (Polyglactin 10). ${ }^{[119]}$ Different ratios of the two monomers allow the tailoring of the polymer properties (e.g., thermomechanical, wettability, swelling and degradation), which is an advantage of PLGA over PGA. ${ }^{[119]}$ The ability to manipulate the degradation ratio, which allows tailoring the material for different types and sizes of nerve gaps, turns PLGA a very attractive material for peripheral nerve regeneration.

PLGA is biodegradable, and releases acidic products during degradation, which presents the deleterious effect described above.

In NGC production, PLGA has been tested as the core material of the conduit and also in combination with others (e.g., collagen). When used alone, in order to turn it permeable and with an adequate porosity, some approaches have been tested, namely the addition of a porogen agent ${ }^{[120]}$ and preparation of hollow fiber membranes using a phase-inversion process. ${ }^{[121]}$ In both works, interesting mechanical properties and degradation profiles were achieved. In a more recent study, a PLGA based catheter was prepared. ${ }^{[122]}$ This catheter comprises an outer tube which has a scaffold inside. This scaffold has many tube shaped structures in order to correctly guide the new nerve fibers. The outside tube provides the mechanical support required for nerve regeneration. As a result, fibroblast growth was facilitated across the inner scaffold and also the outer structure showed good capacity to overcome compression. ${ }^{[122]}$ PLGA had also been electrospun and then coated with a conductive polymer, Ppy. An in vitro assessment with PC12 rat cells showed the formation of longer neuritis compared with the control..[123] In another approach, PLGA conduits were coated with nanosilver to benefit from silver's antimicrobial effect which resulted in an increase of infection resistance of the conduit. ${ }^{[124]} \mathrm{A}$ combination of electrospun PCL with nanospheric PLGA was also tested with PC12 rat cells, revealing long and guided neuritis due to the alignment provided by the scaffold. ${ }^{[125]}$

Neurotrophic factors, as well as Schwann cells, have also been incorporated in PLGA matrices leading to good results, but only in small gaps. Nevertheless, PLGA does not represent a good alternative for peripheral nerve regeneration in general, as only some specific cases can be treated with this polymer. Table 7 shows the main conclusions of the works reported in literature that used this polymer in nerve regeneration.

PCL and P(DLLA-co-CL): PCL is a bioresorbable, hydrophobic and semi-crystalline polyester. ${ }^{[131]}$ Its tailorable degradation and mechanical properties, along with its good compatibility, have made this polymer very attractive to the biomedical field since the 1970s. During this time, it was used in various drug delivery systems, but as its degradation rate was slow, other resorbable polymers as PGA and poly(D,L-lactide) (PDLA) were preferred for this kind of applications. ${ }^{[132]}$ However, since the 2000s, as tissue engineering arose, PCLs has been extensively tested both in vitro and in vivo revealing good results in terms of biocompatibility. As a result, FDA approved its use in tissue engineering applications. ${ }^{[133]}$

For peripheral nerve regeneration, this polymer, in similarity with other bioabsorbable polymers, has been tested in

Table 7. PLGA based NGCs tested in vivo.

\begin{tabular}{|c|c|c|c|c|c|c|}
\hline Year & Material & Nerve & Gap (mm) & Animal & Results & Ref \\
\hline 2004 & PLGA(85:15)+Schwann cells & sciatic & 10 & Rat & $\begin{array}{l}\text { Ultrasonic stimulation has a positive effect on seeded Schwann } \\
\text { cells within PLGA conduit }\end{array}$ & [126] \\
\hline 2006 & $\operatorname{PLGA}(75: 25)+$ collagen & peroneal & 15 & rabbit & $\begin{array}{l}\text { PLGA-coated collagen tube showed better regeneration } \\
\text { comparing to vein grafts }\end{array}$ & [119] \\
\hline 2006 & $\operatorname{PLGA}(85: 15)$ & sciatic & 10 & Rat & Asymmetric structure enhance the removal of drained waste & [127] \\
\hline 2007 & PLGA $(90: 10 ; 50: 50)+$ Schwann cells & sciatic & 10 & rat & $\begin{array}{l}\text { Directional permeability has a positive effect in nerve } \\
\text { regeneration through PLGA conduits }\end{array}$ & [5] \\
\hline 2007 & PLGA (90:10) & sciatic & 10 & rat & Axon regeneration similar to Neurolac & [128] \\
\hline 2008 & PLGA/Pluronic F127 & sciatic & 10 & rat & $\begin{array}{l}\text { Regeneration achieved due to good mechanical properties, } \\
\text { permeability and prevention of scar tissue invasion. }\end{array}$ & [129] \\
\hline 2010 & PLGA/Chitosan+CNTF & tibial & 25 & $\operatorname{dog}$ & Favorable conduit for Schwann cell migration and axonal regeneration & [130] \\
\hline
\end{tabular}


Table 8. Recent PCL NGCs tested in vivo.

\begin{tabular}{|c|c|c|c|c|c|c|}
\hline Year & Material & Nerve & Gap (mm) & Animal & Results & Ref \\
\hline 2012 & $\mathrm{PCL}+\mathrm{MSCS}$ & sciatic & 3 & rat & Gastrocnemius muscle was restored while motor function was improved. & [134] \\
\hline 2013 & PCL/Pluronic F127 & sciatic & 10 & rat & $\begin{array}{l}\text { The double stimulation of nerve growth factor (NGF) and low-intensity pulse ultrasound } \\
\text { (US) were more effective in nerve regeneration than single stimulation. }\end{array}$ & [137] \\
\hline 2014 & $\begin{array}{l}\text { PCL/gelatin+stem } \\
\text { cells (SHED) }\end{array}$ & sciatic & 10 & rat & Improved nerve regrowth across the SHED seeded conduit. & [138] \\
\hline 2014 & $\mathrm{PCL} /$ gelatin & sciatic & 5 & rat & $\begin{array}{l}\text { Electrospun PCL is more suitable for in vivo implantation than } \mathrm{PCL} / \text { gelatin } \\
\text { due to poor histology and electrophysiology. }\end{array}$ & [139] \\
\hline 2014 & $\mathrm{PCL}+$ Schwann cells & sciatic & 14 & rat & Electrospun bilayered seeded conduits improve the sprouting of nerve fibers and motor recovery. & [140] \\
\hline
\end{tabular}

conduits alone, mixed with other polymers and seeded with both cells and nerve growth factors. Improvement of the motor function of the sciatic nerve was achieved with a PCL conduit seeded with MSCs. ${ }^{[134]}$ In a study of the topography of the surface and mechanical properties, NGC based on PCL-PVA were prepared by solvent casting. ${ }^{[23]}$ The presence of a grooved structure helped reducing the excessive mechanical properties of the material, approximating it to the ones of the healthy nerve. Another study evaluated the effect of encapsulated neurotrophic factor derived from glial cell (GDNF) embedded in a nerve conduit made with PCL.[135] The bioactivity of GDNF was confirmed and also the sterilization technique proved to be suitable for this material, as it did not alter its structure or porosity percentage. More recently, works including the use of peptides as RGD with PCL based surfaces have also been reported, and promising results were obtained. ${ }^{[136]}$

Table 8 shows some in vivo studies performed with PCL based NGCs.

$\mathrm{P}$ (DLLA-Co-CL) is a polyester made from D,L-lactic acid and $\varepsilon$-caprolactone that has attracted the interest of the researchers for peripheral nerve regeneration. It should be mentioned that problems derived from its degradation in vivo lead to less damage of the surrounding tissue, as their degradation products are less acidic when compared with PGA or PLGA. ${ }^{[128]}$

On the other hand, compared with the other biodegradable materials, P(DLLA-co-CL) is more hydrophobic, which can lead to higher degradation times, extending the life time of the conduit in the body. Moreover, in some cases, even after the nerve is regenerated and functional activity is restored, there still small fragments of the nerve conduits standing by the new nerve. ${ }^{[36]}$ FDA gave approval to a commercial product made from this copolyester known as Neurolac. This conduit has a diameter of 1.5-10 $\mathrm{mm}$ and length of $3 \mathrm{~cm}$. In terms of degradation, it only degrades completely after 16 months. ${ }^{[36]}$

\section{Outlook and Conclusions}

Peripheral nerve injury is a problem affecting millions of people all around the world, with consequences that can lead to irreversible disability. The preparation of a device able to improve the recovery ratios after peripheral nerve injury still remains a clinical challenge. After mid-1980s, some devices received FDA approval, which include those made from natural and synthetic polymers. Unfortunately, none of these devices has all the desirable characteristics for achieving better results, since they present limited repair for gaps longer than $30 \mathrm{~mm}^{[59]}$ and are also somewhat expensive. It is believed that the trend of peripheral nerve regeneration is to create devices, which can be adapted to different gap lengths. Also, the inclusion of exogenous cells to enhance the recovery of the nerve has received considerable interest in the last years showing promising results. Another approach that has been proposed is the use of polymeric materials with conductive properties, namely Ppy. Although some preliminary results have shown that conductive properties are effective in promoting nerve regeneration, in the authors opinion, this property should be attained by modifying biodegradable materials, since Ppy is non-biodegradable. The use of non-biodegradable materials in this application, as mentioned in this manuscript, can be seen as a disadvantage as the material may constrict the new nerve fibers and a second surgical intervention may be needed for its removal.

To sum up, in the authors' opinion, polymeric materials seem to be a reliable solution to prepare such nerve conduits, since their properties can be easily modified and also allow the easy incorporation of nerve growth factors and accessory cells, which play an important role in successful regeneration of the injured nerve.

\section{Acknowledgements}

A. C. Pinho acknowledges "Fundação para a Ciência e Tecnologia", Grant: PD/BD/52626/2014 under the scope of Doctoral Program AdvaMTech. A. C. Fonseca acknowledges "Fundação para a Ciência e Tecnologia", Grant: SFRH/BPD/99982/2014. The authors would like to state that the first version of this manuscript was submitted on June $29^{\text {th }}$ 2015. The comments sent by the reviewers were highly regarded.

Received: March 2, 2016

Published online: September 7, 2016
[1] L. R. Robinson, Muscle Nerve 2000, 23, 863.

[2] S. F. Wang, L. Cai, Int. J. Polym. Sci. 2010, 2010, 1.

[3] B. S, Schlosshauer, E. Muller, B. Schroder, H. Planck, H. W. Muller, Brain Res. 2003, 963, 321.

[4] D. Szarek, K. Marycz, P. Bednarz, P. Tabakow, W. Jarmundowicz, J. Laska, Biotechnol. Appl. Biochem. 2013, 60, 547.

[5] C. J. Chang, S. H. Hsu, H. J. Yen, H. Chang, S. K. Hsu, J. Biomed. Mater. Res. Part B 2007, 83B, 206. 
[6] L. L. Gong, Y. Zhu, X. Xu, H. Q. Li, W. M. Guo, Q. Zhao, D. B. Yao, Neural Regen. Res. 2014, 9, 2151.

[7] J. S. Belkas, M. S. Shoichett, R. Midha, Neurol. Res. 2004, 26, 151.

[8] M. Y. Li, P. A. Zhang, W. M. Guo, H. Q. Li, X. S. Gu, D. B. Yao, Muscle Nerve 2014, 50, 73.

[9] L. Conforti, J. Gilley, M. P. Coleman, Nat. Rev. Neurosci. 2014, 15, 394.

[10] S. Kapur, S. Poore, in Extremity Replantation, (Eds: A. N. Salyapongse, S. O. Poore, A. M. Afifi, M. L. Bentz), Springer, New York, US 2015, 25.

[11] A. Pabari, S. Y. Yang, A. Mosahebi, A. M. Seifalian, J. Control. Release 2011, 156, 2.

[12] H. Millesi, Hand 1973, 5, 157.

[13] R. V. Weber, S. E. Mackinnon, Clin. Plast. Surg. 2005, 32, 605.

[14] Y. Kaya, L. Sarikcioglu, Childs Nerv. Syst. 2015, 31, 177.

[15] S. Sunderland, Brain 1951, 74, 491.

[16] A. Pabari, S. Y. Yang, A. M. Seifalian, A. Mosahebi, J. Plast. Reconstr. Aesthet. Surg. 2010, 63, 1941.

[17] Y. Demir, in Plast. Reconstr. Surg., (Ed: M. Z. Siemionow), Springer, London 2015, 455.

[18] C. Vanglair, Arch. Biol. 1882, 3, 379.

[19] A. Faroni, S. A. Mobasseri, P. J. Kingham, A. J. Reid, Adv. Drug Delivery Rev. 2015, 82/83, 160.

[20] G. C. de Ruiter, M. J. Malessy, M. J. Yaszemski, A. J. Windebank, R. J. Spinner, Neurosurg. Focus 2009, 26, E5.

[21] W. Daly, L. Yao, D. Zeugolis, A. Windebank, A. Pandit, J. R. Soc. Interface 2012, 9, 202.

[22] C. M. Owens, F. Marga, G. Forgacs, C. M. Heesch, Biofabrication 2013, 5, 045007

[23] S. A. Mobasseri, G. Terenghi, S. Downes, J. Mater. Sci.- Mater. Med. 2013, 24, 1639.

[24] L. Luo, L. Gan, Y. Liu, W. Tian, Z. Tong, X. Wang, C. Huselstein, Y. Chen, Biochem. Biophys. Res. Commun. 2015, 457, 507.

[25] T. Ren, S. Yu, Z. Mao, C. Gao, Biomaterials 2015, 56, 58.

[26] V. Chiono, C. Tonda-Turo, Prog. Neurobiol. 2015, 131, 87.

[27] N. Diban, D. Stamatialis, J. Chem. Technol. Biotechnol. 2014, 89, 633.

[28] X. Gu, F. Ding, Y. Yang, J. Liu, Prog. Neurobiol. 2011, 93, 204.

[29] S. Ichihara, Y. Inada, T. Nakamura, Injury 2008, 39, Suppl 4, 29.

[30] W. Xiangmei, Z. Jing, C. Hao, W. Qingrui, J. Appl. Polym. Sci. 2009, 112, 3652.

[31] X. Jiang, S. H. Lim, H.-Q. Mao, S. Y. Chew, Exp. Neurol. 2010, 223, 86.

[32] E. C. Spivey, Z. Z. Khaing, J. B. Shear, C. E. Schmidt, Biomaterials 2012, 33, 4264

[33] A. Goraltchouk, V. Scanga, C. M. Morshead, M. S. Shoichet, J. Controlled Release 2006, 110, 400.

[34] M. D. Wood, A. M. Moore, D. A. Hunter, S. Tuffaha, G. H. Borschel, S. E. Mackinnon, S. E. Sakiyama-Elbert, Acta Biomater. 2009, 5, 959.

[35] M. D. Wood, M. R. MacEwan, A. R. French, A. M. Moore, D. A. Hunter, S. E. Mackinnon, D. W. Moran, G. H. Borschel, S. E. Sakiyama-Elbert, Biotechnol. Bioeng. 2010, 106, 970.

[36] S. Kehoe, X. F. Zhang, D. Boyd, Injury 2012, 43, 553.

[37] W. Z. Ray, S. E. Mackinnon, Exp. Neurol. 2010, 223, 77.

[38] M. Siemionow, M. Bozkurt, F. Zor, Microsurgery 2010, 30, 574.

[39] X. Wang, W. Hu, Y. Cao, J. Yao, J. Wu, X. Gu, Brain 2005, 128, 1897.

[40] A. E. Einige, Wien Med. Presse 1885, 26, 1285.

[41] S. H. Keshel, E. Bialzar, A. Sahebalzamani, M. Heidari, Int. J. Polym. Mater. Polym. Biomater. 2014, 63, 753.

[42] D. J. Gerth, J. Tashiro, S. R. Thaller, World J. Clin. Cases 2015, 3, 141.

[43] P. Konofaos, J. P. Ver Halen, J. Reconstr. Microsurg. 2013, 29, 149.

[44] J. B. Tang, Y. Q. Gu, Y. S. Song, J. Hand Surg. 1993, 18, 449.

[45] H. Kraus, H. Reisner, Arch. Klin. Chir. 1940, 199, 318.

[46] J. Brandt, L. B. Dahlin, G. Lundborg, J. Hand Surg.-Br. Eur. Vol. 1999, 24B, 284.
[47] D. T. W. Chiu, I. Janecka, T. J. Krizek, M. Wolff, R. E. Lovelace, Surgery 1982, 91, 226.

[48] D. H. Rice, F. D. Berstein, Otolaryngol. Head Neck Surg. 1984, 92, 410.

[49] P. N. Anderson, M. Turmaine, J. Anat. 1986, 147, 73.

[50] J. W. Fawcett, R. J. Keynes, J. Neurosurg. 1986, 65, 354.

[51] J. Smahel, B. Jentsch, Ann. Plast. Surg. 1986, 16, 494.

[52] D. T. Chiu, R. E. Lovelace, L. T. Yu, M. Wolff, S. Stengel, L. Middleton, I. P. Janecka, T. J. Krizek, J. Reconstr. Microsurg. 1988, 4, 303.

[53] G. Risitano, G. Cavallaro, M. Lentini, J. Hand Surg.-Br. Eur. Vol. 1989, 14B, 102.

[54] M. Ochi, Y. Ikuta, Y. Miyamoto, S. Takeno, Exp. Neurol. 1992, 115, 260.

[55] T. E. J. Hems, M. A. Glasby, Br. J. Plast. Surg. 1992, 45, 497.

[56] K. K. Wang, P. D. Costas, D. J. Bryan, D. S. Jones, B. R. Seckel, Microsurgery 1993, 14, 608.

[57] J. Benito-ruiz, A. Navarro-monzonis, A. Piqueras, P. Baenamontilla, Microsurgery 1994, 15, 105.

[58] P. Tos, B. Battiston, S. Nicolino, S. Raimondo, M. Fornaro, J. M. Lee, L. Chirila, S. Geuna, I. Perroteau, Microsurgery 2007, 27, 48.

[59] O. Alluin, C. Wittmann, T. Marqueste, J. F. Chabas, S. Garcia, M. N. Lavaut, D. Guinard, F. Feron, P. Decherchi, Biomaterials 2009, 30, 363.

[60] F. Ma, Z. Xiao, D. Meng, X. Hou, J. Zhu, J. Dai, R. Xu, Int. J. Mol. Sci. 2014, 15, 18593

[61] A. C. Fonseca, P. Ferreira, R. A. Cordeiro, P. V. Mendonça, J. R. Góis, M. H. Gil, J. F. J. Coelho, in New Strategies to Advance Pre/Diabetes Care: Integrative Approach by PPPM, (Eds: M. S. Mozaffari), Springer, Dordrecht 2011, Ch. 16.

[62] W. A. Gibby, H. R. Koerber, K. W. Horch, J. Neurosurg. 1983, 58, 574.

[63] J. M. Rosen, J. A. Padilla, K. D. Nguyen, M. A. Padilla, E. E. Sabelman, H. N. Pham, Ann. Plast. Surg. 1990, 25, 375.

[64] S. J. Archibald, C. Krarup, J. Shefner, S. T. Li, R. D. Madison, J. Comp. Neurol. 1991, 306, 685.

[65] H. Okamoto, K. Hata, H. Kagami, K. Okada, Y. Ito, Y. Narita, H. Hirata, I. Sekiya, T. Otsuka, M. Ueda, J. Biomed. Mater. Res., Part A 2010, 92, 859.

[66] T. Dienstknecht, S. Klein, J. Vykoukal, S. Gehmert, M. Koller, M. Gosau, L. Prantl, J. Hand Surg. 2013, 38, 1119.

[67] A. Haug, A. Bartels, J. Kotas, E. Kunesch, J. Hand Surg. 2013, 38, 90.

[68] G. Giusti, R. H. Shin, J.-Y. Lee, T. G. Mattar, A. T. Bishop, A. Y. Shin, Microsurgery 2014, 34, 646.

[69] M. Patel, L. Mao, B. Wu, P. VandeVord, J. Biomed. Mater. Res., Part A 2009, 90, 154.

[70] G. Wang, G. Lu, Q. Ao, Y. Gong, X. Zhang, Biotechnol. Lett. 2010, $32,59$.

[71] T. Freier, R. Montenegro, H. Shan Koh, M. S. Shoichet, Biomaterials 2005, 26, 4624.

[72] L. Zhang, Q. Ao, A. Wang, G. Lu, L. Kong, Y. Gong, N. Zhao, X. Zhang, J. Biomed. Mater. Res., Part A 2006, 77, 277.

[73] K. Haastert-Talini, S. Geuna, L. B. Dahlin, C. Meyer, L. Stenberg, T. Freier, C. Heimann, C. Barwig, L. F. Pinto, S. Raimondo, G. Gambarotta, S. R. Samy, N. Sousa, A. J. Salgado, A. Ratzka, S. Wrobel, C. Grothe, Biomaterials 2013, 34, 9886.

[74] Y. Yang, W. Zhao, J. He, Y. Zhao, F. Ding, X. Gu, Eur. J. Pharm. Biopharm. 2011, 79, 519.

[75] A. Wang, Q. Ao, W. Cao, M. Yu, Q. He, L. Kong, L. Zhang, Y. Gong, X. Zhang, J. Biom. Mater. Res., Part A 2006, 79, 36.

[76] G. Li, L. Zhang, C. Wang, X. Zhao, C. Zhu, Y. Zheng, Y. Wang, Y. Zhao, Y. Yang, Carbohydr. Polym. 2014, 101, 718.

[77] Y. Yuan, P. Zhang, Y. Yang, X. Wang, X. Gu, Biomaterials 2004, 25, 4273.

[78] J. Zhu, Y. Xiong, C. Zeng, N. Qiang, D. Quan, J. Wan, Int. J. Biol. Macromol. 2012, 51, 105. 
[79] Y. M. Yang, X. S. Gu, R. X. Tan, W. Hu, W. Hu, X. D. Wang, P. Y. Zhang, T. Y. Zhang, Biotechnol. Lett. 2004, 26, 1793.

[80] M. E. Chavez-Delgado, U. Gomez-Pinedo, A. Feria-Velasco, M. Huerta-Viera, S. C. Castaneda, F. A. Toral, A. Parducz, S. L. Anda, J. Mora-Galindo, J. Garcia-Estrada, J. Biomed. Mater. Res., Part B 2005, 74, 589.

[81] W. Xiao, X. Y. Hu, W. Zeng, J. H. Huang, Y. G. Zhang, Z. J. Luo, Injury 2013, 44, 941.

[82] N. Tanaka, I. Matsumoto, M. Suzuki, M. Kaneko, K. Nitta, R. Seguchi, A. Ooi, H. Takemura, Interact. Cardiovasc. Thorac. Surg. 2015, 21, 8 .

[83] M. Aberg, C. Ljungberg, E. Edin, H. Millqvist, E. Nordh, A. Theorin, G. Terenghi, M. Wiberg, J. Plast. Reconstr. Aesthet. Surg. 2009, 62, 1503

[84] A. Hazari, G. Johansson-Ruden, K. Junemo-Bostrom, C. Ljungberg, G. Terenghi, C. Green, M. Wiberg, J. Hand Surg. 1999, 24, 291.

[85] D. Arslantunali, T. Dursun, D. Yucel, N. Hasirci, V. Hasirci, Med. Devices: Evidence Res. 2014, 7, 405.

[86] E. Masaeli, M. Morshed, M. H. Nasr-Esfahani, S. Sadri, J. Hilderink, A. van Apeldoorn, C. A. van Blitterswijk, L. Moroni, PLOS ONE 2013, 8, e57157.

[87] M. Sahebalzamani, E. Biazar, M. Shahrezaei, H. Hosseinkazemi, H. Rahiminavaie, Int. J. Polym. Mater. Polym. Biomater. 2015, 64, 149.

[88] J. L. Drury, D. J. Mooney, Biomaterials 2003, 24, 4337.

[89] H. L. J. Chaw, Y. Shih, C. Huang, Bio-Med. Mater. Eng. 2015, 26, 95.

[90] L. N. Novikova, A. Mosahebi, M. Wiberg, G. Terenghi, J. O. Kellerth, L. N. Novikov, J. Biomed. Mater. Res., Part A 2006, 77, 242.

[91] L. A. Pfister, M. Papaloizos, H. P. Merkle, B. Gander, J. Biomed. Mater. Res., Part A 2007, 80, 932.

[92] M. Merle, A. Dellon, J. Campbell, P. Chang, Microsurgery 1989, 10, 130.

[93] Y. S. Chen, C. L. Hsieh, C. C. Tsai, T. H. Chen, W. C. Cheng, C. L. Hu, C. H. Yao, Biomaterials 2000, 21, 1541.

[94] G. Lundborg, L. Dahlin, N. danielsen, J. Plast. Reconstr. Surg. 1991, $25,79$.

[95] G. Lundborg, B. Rosén, L. Dahlin, N. Danielsen, J. Holmberg, J. Hand Surg. Am. 1997, 22, 99.

[96] G. Lundborg, B. Rosén, S. Abrahamson, L. Dahlin, N. Danielsen, J. Hand Surg. 1994, 19, 273.

[97] G. Lundborg, L. B. Dahlin, N. Danielsen, R. H. Gelberman, F. M. Longo, H. C. Powell, S. Varon, Exp. Neurol. 1982, 76, 361.

[98] M. Ochi, Hiroshima J. Med. Sci. 1983, 32, 389.

[99] L. R. Williams, H. C. Powell, G. Lundborg, S. Varon, Brain Res. 1984, 293, 201.

[100] K. L. Gibson, J. K. Daniloff, Microsurgery 1989, 10, 126.

[101] P. C. Francel, T. J. Francel, S. E. Mackinnon, C. Hertl, J. Neurosurg. 1997, 87, 887.

[102] S. Azizi, R. Mohammadi, K. Amini, R. Fallah, K. Karegar, Vet. Res. Forum 2012, 1, 107.

[103] R. Ikeguchi, R. Kakinoki, H. Tsuji, T. Yasuda, S. Matsuda, Appl. Surf. Sci. 2014, 310, 19.

[104] M. Pitta, L. Wolford, P. Mehra, J. Hopkin, J. Oral Maxillofac. Surg. 2001, 59, 493.

[105] Z. Shi, H. Gao, J. Feng, B. Ding, X. Cao, S. Kuga, Y. Wang, L. Zhang, J. Cai, Angew. Chem., Int. Ed. 2014, 53, 5380.

[106] B. C. Thompson, S. E. Moulton, R. T. Richardson, G. G. Wallace, Biomaterials 2011, 32, 3822.

[107] J. Ai, A. Kiasat-Dolatabadi, S. Ebrahimi-Barough, A. Ai, N. Lotfibakhshaiesh, A. Norouzi-Javidan, H. Saberi, B. Arjmand, H. R. Aghayan, Arch. Neurosci. 2014, 1, 15.

[108] C. E. Schmidt, V. R. Shastri, J. P. Vacanti, R. Langer, Proc. Natl. Acad. Sci. 1997, 94, 8948.
[109] N. Gomez, J. Y. Lee, J. D. Nickels, C. E. Schmidt, Adv. Funct. Mater. 2007, 17, 1645

[110] H. Xu, J. M. Holzwarth, Y. Yan, P. Xu, H. Zheng, Y. Yin, S. Li, P. X. Ma, Biomaterials 2014, 35, 225.

[111] J. Ribeiro, T. Pereira, A. R. Caseiro, P. Armada-da-Silva, I. Pires, J. Prada, I. Amorim, S. Amado, M. França, C. Gonçalves, M. A. Lopes, J. D. Santos, D. M. Silva, S. Geuna, A. L. Luís, A. C. Maurício, World J. Stem Cells 2015, 7, 956.

[112] F. Yang, R. Murugan, S. Ramakrishna, X. Wang, Y. Ma, S. Wang, Biomaterials 2004, 25, 1891.

[113] S. Mackinnon, A. Dellon, Plast. Reconstr. Surg. 1990, 85, 419.

[114] W. Hu, J. Gu, A. Deng, X. Gu, Biotechnol. Lett. 2008, 30, 1937.

[115] T. Kiyotani, T. Nakamura, Y. Shimizu, K. Endo, Asaio J. 1995, 41, M657.

[116] K. Matsumoto, K. Ohnishi, T. Kiyotani, T. Sekine, H. Ueda, T. Nakamura, K. Endo, Y. Shimizu, Brain Res. 2000, 868, 315.

[117] T. Waitayawinyu, D. M. Parisi, B. Miller, S. Luria, H. J. Morton, S. H. Chin, T. E. Trumble, J. Hand Surg. Am 2007, 32A, 1521.

[118] T. Nakamura, Y. Inada, S. Fukuda, M. Yoshitani, A. Nakada, S. Itoi, S. Kanemaru, K. Endo, Y. Shimizu, Brain Res 2004, 1027, 18.

[119] D. Y. Lee, B. H. Choi, J. H. Park, S. J. Zhu, B. Y. Kim, J. Y. Huh, S. H. Lee, J. H. Jung, S. H. Kim, J. Craniomaxillofac. Surg. 2006, 34, 50.

[120] Y. Yang, L. De Laporte, C. B. Rives, J.-H. Jang, W.-C. Lin, K. R. Shull, L. D. Shea, J. Controlled Release 2005, 104, 433.

[121] X. Wen, P. A. Tresco, Biomaterials 2006, 27, 3800

[122] B. Wang, P. Zhang, W. Song, L. Zhao, C. He, Text. Res. J. 2015, 85, 51.

[123] J. Y. Lee, C. A. Bashur, A. S. Goldstein, C. E. Schmidt, Biomaterials 2009, 30, 4325 .

[124] N. Doubra, A. Amiri, M. F. Koudehi, Z. Jamalpoor, A. A. I. Fooladi, N. M. Reza, J. Appl. Tissue Eng. 2014, 1, 13.

[125] W. Zhu, F. Masood, J. O'Brien, L. G. Zhang, Nanomedicine: NBM 2015, 11, 693 .

[126] C. J. Chang, S. H. Hsu, Ultrasound Med. Biol. 2004, 30, 1079.

[127] C. J. Chang, S. H. Hsu, Biomaterials 2006, 27, 1035.

[128] A. L. Luis, J. M. Rodrigues, S. Amado, A. P. Veloso, P. A. S. Armada-Da-Silva, S. Raimondo, F. Fregnan, A. J. Ferreira, M. A. Lopes, J. D. Santos, S. Geuna, A. S. P. Varejao, A. C. Mauricio, Microsurgery 2007, 27, 125.

[129] S. H. Oh, J. H. Kim, K. S. Song, B. H. Jeon, J. H. Yoon, T. B. Seo, U. Namgung, I. W. Lee, J. H. Lee, Biomaterials 2008, 29, 1601.

[130] H. Shen, Z.-L. Shen, P.-H. Zhang, N.-L. Chen, Y.-C. Wang, Z.-F. Zhang, Y.-Q. Jin, J. Biomed. Mater. Res., Part B 2010, 95B, 161.

[131] J. M. Williams, A. Adewunmi, R. M. Schek, C. L. Flanagan, P. H. Krebsbach, S. E. Feinberg, S. J. Hollister, S. Das, Biomaterials 2005, 26, 4817.

[132] M. A. Woodruff, D. W. Hutmacher, Prog. Polym. Sci. 2010, 35, 1217.

[133] D. W. Hutmacher, T. Schantz, I. Zein, K. W. Ng, S. H. Teoh, K. C. Tan, J. Biomed. Mater. Res. 2001, 55, 203.

[134] F. Frattini, F. R. P. Lopes, F. M. Almeida, R. F. Rodrigues, L. C. Boldrini, M. A. Tomaz, A. F. Baptista, P. A. Melo, A. M. B. Martinez, Tissue Eng., Part A 2012, 18, 2030.

[135] J. M. Bliley, W. N. Sivak, D. M. Minteer, C. Tompkins-Rhoades, J. Day, G. Williamson, H. T. Liao, K. G. Marra, ACS Biomater. Sci. Eng. 2015, 1, 504.

[136] T. Sedaghati, G. Jell, A. Seifalian, New Biotechnol. 2014, 31, 203.

[137] J. R. Kim, S. H. Oh, G. B. Kwon, U. Namgung, K. S. Song, B. H. Jeon, J. H. Lee, Tissue Eng., Part A 2013, 19, 2674.

[138] M. H. Beigi, L. Ghasemi-Mobarakeh, M. P. Prabhakaran, K. Karbalaie, H. Azadeh, S. Ramakrishna, H. Baharvand, M.-H. Nasr-Esfahani, J. Biomed. Mater. Res., Part A 2014, 102, 4554.

[139] V. Cirillo, B. A. Clements, V. Guarino, J. Bushman, J. Kohn, L. Ambrosio, Biomaterials 2014, 35, 8970.

[140] J. Xie, M. R. MacEwan, W. Liu, N. Jesuraj, X. Li, D. Hunter, Y. Xia, ACS Appl. Mater. Interfaces 2014, 6, 9472. 